potentially pathogenic organism which might be used industrially must be deposited with them.

The difficulty of proving identity between cultures, exaggerated by the propensity of microorganisms to change in culture, poses practical and philosophical problems for patent law. The ability to specify genetic sequences precisely in terms of their nucleotide sequence could provide a basis for criteria of identity, as $\operatorname{Dr} R$. Hill of the National Type Culture Collection pointed out, but the problem of what constitutes a sufficient difference in patent law would still remain.

Patent law has not yet got to grips with the problem of geneticallyengineered bacteria, both in terms of their patentability and of the particular

\section{Sweden's sunny future}

How might Sweden's energy be supplied in the year 2015? A report, 'Solar or uranium-to choose an energy future', shortly to be published by the Secretariat for Future Studies, describes two alternatives. Each costs the same and each gives everyone in the country the material standard of living of today's top $10 \%$ of the population. The uranium alternative would mean 70 nuclear reactors, half of them breeders. Under the solar alternative, energy would come from biomass, solar cells, hydropower, windpower and solar heating.

The assumptions in the report are that the population in 2015 will be the same as it is today-about eight million; that energy demand will be reduced to $80 \%$ of today's in industry (which agrees with the official prognosis for the year 1995), to $50 \%$ of today's in the service sector (transport of people and goods, commerce and government services such as education), and to $70 \%$ of today's for housing (mainly space heating).

Under the solar alternative, $351 \mathrm{TWh}$ would be supplied by biomass and converted to the demand sector by fuel cells, the production of methanol and district heating cogeneration. The energy plantations needed would cover 2.9 million hectares (about 6-7\% of Sweden's total land area), with an average production of $90 \mathrm{MWh}$ per hectare per year. Solar cells would

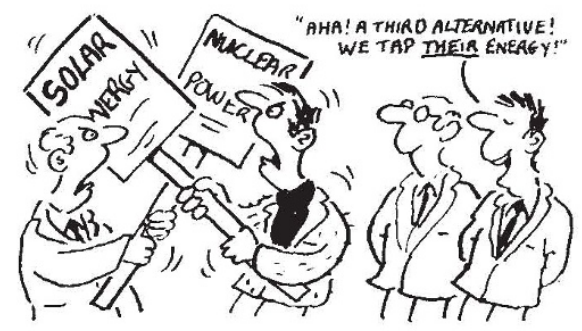

difficultics there might be in storing bacteria whose claim to originality lies in the properties possessed by a plasmid, which in some circumstances could be lost from its bacterial host. What should be patented--the recombinant plasmid itself or the combination of plasmid and bacterium? When will the techniques of genetic manipulation be sufficiently standard and the outcome sufficiently predictable for the product not to be patentable without some further original twist? G. S. A. Szabo, Patents Manager for the Wellcome Foundation, encouraged his audience to test the patent system with applications. As always however it looks as though the chief beneficiaries will be the lawyers.

Eleanor Lawrence

supply a total of $50 \mathrm{TWh}$. Some would be connected directly to their loads; others would be used for the production of methanol; still others for seasonal storage of energy. Hydropower would yield $65 \mathrm{TWh}$, as compared to its present $57 \mathrm{TWh}$ (a limited expansion, taking into account environmentalists' objections to the building of more plants). Windpower would contribute $30 \mathrm{TWh}$ from 3700 units. Solar heating would be mainly used for space heating and would supply $71 \mathrm{TWh}$. The sun shines on Sweden for 1,500-2,000 hours a year $(40 \%$ as much as North Africa), but because practically all of them are between May and September, storage systems would be needed to keep summer's heat for winter. The authors estimate that a 500,000-cubic metre reservoir of water would be able to store enough heat for several apartments in a district heating system.

At the moment, renewable sources provide $24 \%$ of Sweden's energy. Assuming that the first production units in all the renewable-source systems could be operating in 1990 , the report foresees them providing $50 \%$ of the country's energy by the year 2000 and $100 \%$ by 2015 .

The actual setting up of such a system would be far from simple, given the political pressures that exist for expanding nuclear power. Some of the possible snags the authors discuss are their assumptions that the research and development now being done into renewable energy technologies will be successful, and the inevitable clashes over land use. But it was partially to point out the snags of both energy systems that the authors, engineers Peter Steen and Måns Lönnroth and theoretical physicist Thomas Johansson. wrote the report.

\section{Success for unified field theory}

"I think the unification is there and we really have three forces of nature" said Abdus Salam last week. He was referring to a result, a closely guarded secret, announced last Monday (12 June) at the Stanford Linear Acceleraor Center in California, which vindicated the unified field theory of the weak and clectromagnetic interactions developed independently in 1967 and 1968 by himself and Steven Weinberg.

Threc hundred people crammed into the SLAC seminar room to hear the result, announced by $\mathrm{Dr}$ Richard Taylor and his group. Even Salam (of Imperial (ollege, London) and Weinberg (of Harvard) had not been told what the result would be. In the event, their theory was confirmed, there was not a single question on experimental technique, and the experimenters received a standing ovation.

Dr Taylor also lead the group which in the late 1960s had shown that there were tiny, hard objects within protons and neutrons. These are now universally believed to be quarks. In that experiment Taylor had fired high energy electrons at protons and measured their scattering, rather as Rutherford had fired alpha particles at atoms and discovered the nucleus. This time the electrons were polarised-with their intrinsic spin pointing in a fixed direction-but otherwise the experiment was the same.

The polarisation enabled the group to determine if the interaction of electron and proton showed any distinction hetween right and left. The Weinberg-Salam model predicted that it should, and in conjunction with neutrino experiments which had set the scale for the so-called 'parity breaking' between right and left, there was a precise prediction of the amount of parity breaking that should be seen in the SLAC experiments. Just this amount. which comes from interference within the model between the parity-violating weak force and electromagnetism. was observed.

"In a sense a chapter is closed" said Salam. Neutrino experiments had been converging on the Weinberg-Salam model. "The degree of agreement was uncanny". But two atomic physics experiments, measuring the same effect as the SLAC experiment, disagreed with the neutrino results, so all was not roses. These results still stand, but high energy physicists will feel more inclined to accept the rather clean experiment from SLAC, than the ingenious, but complex, experiments from Oxford and Seattle. More about this in News and Views soon.

Robert Walgate 